DOI: 10.12731/wsd-2017-2-54-69

УДК 616-092-18

\title{
ОПЫТ ИСПОЛЬЗОВАНИЯ СВЕТОДИОДНОГО ИЗЛУЧЕНИЯ В ХИРУРГИИ И ДРУГИХ РАЗДЕЛАХ МЕДИЦИНЫ
}

Байбеков И.М., Карташев В.П., Пулатов Д.Т., Бутаев А.Х.

Цель. Изучить опыт использования светодиодного излучения (Light Emitting Diode - LED) в хирургии и других разделах медицины.

Методы и методология. Методологическую основу составил анализ литературы, синтез результатов экспериментальных и клинических исследований, а также современная трактовка механизмов действия низкоинтенсивного лазерного излучения и LED воздействий на организм. Особое внимание уделено опыту клинико-морфологических исследований LED-воздействий, проводимых в Республиканском специализированном иентре хирургии им. академика В. Вахидова Министерства здравоохранения Республики Узбекистан.

Результаты. Представлена сравнительная характеристика стимулирующих репаративные прочессы свойств лазеров и LED, их влияние на заживление кожных ран и грудины после стернотомии, эритроцииты и микроциикуляциию.

Заключение. Высказывается мнение, что светодиодное излучение является альтернатива лазеров. Использование светодиодного излучения иелесообразно в комплексном лечении хирургических болезней.

Ключевые слова: фототерапия; светодиоды LED; LED в хирургии.

\section{APPLICATION OF LIGHT EMITTING DIODE IRRADIATION IN SURGERY AND OTHER FIELDS OF MEDICINE}

Baybekov I.M., Kartashev V.P., Pulatov D.T., Butaev A.Kh.

Goal. To study the experience of using Light Emitting Diode (LED) in surgery and other areas of medicine. 
Methods and methodology. The methodological basis is the analysis of literature, synthesis of the results of experimental and clinical studies, as well as a modern interpretation of the mechanisms of action of low-intensity laser radiation and LED effects on the body. Special attention is paid to the experience of clinical and morphological studies LED of impacts at the Republican specialized center of surgery named academician $V$. Vahidov of the Ministry of health of the Republic of Uzbekistan.

Results. Comparative features of LED and lasers, such as stimulation of reparative processes, their influence on healing of skin wounds and sternum after sternotomy, red blood cells and microcirculation are discussed.

Conclusion. It has been suggested that LED is a worthy alternative to lasers. Their use is advisable in complex treatment of surgical diseases.

Keywords: phototherapy; light diodes LED; application LED in surgery.

Световые воздействия (фототерапия) издавна применяются в лечении различных заболеваний. Как справедливо отмечает С.В. Москвин, использование естественного света в лечебных целях, вероятно, так же старо, как само человечество [23]. Гиппократ - «отец» медицинской науки был первым врачом, указавшим на пользу солнцелечения. Абу Али Ибн Сино на страницах своего многотомного «Канона врачебной науки», до сегодняшних дней не утратившим своего значения, неоднократно упоминает о роли солнечных лучей в лечении и профилактике болезней.

Первое, обоснованное с точки зрения современной медицинской науки, использование фототерапии в дерматологии и вообще в медицине принадлежит датскому физиотерапевту Финсену. Им были разработаны основы применения фототерапии (ультрафиолетового излучения) для лечения красной волчанки. Затем Финсен доказал эффективность красного света для лечения кожной оспы. За это Финсену, одному из первых врачей, в 1903 году была присуждена Нобелевская премия в области медицины.

Прогресс в использовании различных видов фототерапии в медицине и, в частности в хирургии, связан с общим прогрессом науки. Создание квантовой теории излучения А. Эйнштейном и П. Дираком стали предтечей появления квантовых генераторов. В.А. Фабрикант в 1939 году обосновал способ усиления света и определил условия необходимые для усиления излучения при помощи вынужденного испускания. Плодами этих теоретических разработок явилось создание квантовых генераторов - мазеров и лазеров. В настоящее время со школьной скамьи извест- 
на аббревиатура LASER - Light Amplification by Stimulated Emission of Radiation - усиление света в результате вынужденного излучения.

Н.Г. Басов, А.М. Прохоров и Ч. Таунс за создание первых квантовых усилителей и генераторов СВЧ-диапазонов получили в 1964 году Нобелевскую премию по физике [23, 42]. Благодаря фундаментальным исследованиям Ж.И. Алферова в области полупроводников, в 1960-х годах были созданы полупроводниковые лазеры. В 2000 году за эти разработки, он был удостоен Нобелевской премии. Они легли в основу создания и светодиодных излучателей (Light Emitting Diode - LED) [23, 41, 42]. Таким образом, в основе современных квантовых технологий, определившей широкое использование лазеров и светодиодов во всех сферах деятельности человечества, включая медицину, лежат крупнейшие научные открытия нашего времени.

В этом аспекте создание специальных приборов на основе квантовых технологий - лазеров для использования во всех областях медицины по темпам их внедрения в лечебную практику несравнимо ни с одним достижением человеческого разума. В медицине лазеры широко используются, как в лечении и диагностике, так и профилактике подавляющего большинства болезней и патологических состояний. Они применяются в хирургии, офтальмологии, стоматологии, кардиологии, акушерстве и гинекологии, урологии, онкологии и др.

После рубинового лазера созданного Т. Мейманом и являющимся первым лазером, использованным в медицине, наиболее популярными лазерами, которые использовались для лечения различных заболеваний, стали гелий-неоновые лазеры (ГНЛ). Они, или их полупроводниковые аналоги, генерирующие излучение аналогичной длины волны - $633 \mathrm{~nm}$ (в красном диапазоне) широко используются и в настоящее время, как для локального воздействия на зону поражения, так и облучения крови. В настоящее время число лазеров, используемых в медицине, достигло несколько десятков. Они используются как для лечения, так и диагностики $[1-9,11,13,15-18,20,21,24-26,28,30-32,34]$.

В этом аспекте Лазерная Доплеровская Флоуметрия (ЛДФ) является наиболее объективным методом оценки микроциркуляции, так как позволяет получать более 20 -ти её параметров [2, 18, 20, 29, 35, 40]. В последние годы в медицине всё шире используется, светодиодное излучение - Light Emitting Diode (LED) [5, 10, 19, 36, 37, 38, 39]. Z. Simunovic, Tuner и Hode дали сравнительную характеристику основных лазеров и LED-генераторов, используемых в медицине [37]. Показано, что эффек- 
тивность LED излучателей, при их использовании в различных сферах медицины, лишь незначительно уступает лазерам. Результаты изучения LED-технологий влияния на биологические объекты, в том числе в космосе, позволили FDA (Food and Drug Administration) США одобрить их применение в медицине [36, 37, 38, 39].

Одним из пионеров создания и внедрения в медицину различных типов LED-генераторов в СНГ является A.M. Коробов, руководитель НИИ лазерной биологи и медицины при Харьковском национальном университете им В.Н. Каразина [19]. Под его руководством создана большая серия гибких фотонно-магнитных матриц серии Барва-Флекс, включая одеяла и ортопедические матрацы, а также сапожки для лечения диабетический стопы и других приспособлений. Использование светодиодного излучения матриц серии Барва-Флекс, показало высокую эффективность этого вида фототерапии при различных видах патологии, в том числе в хирургии, включая и так называемую, эстетическую хирургию $[5,19,36,37]$.

Сравнительная оценка и выбор наиболее эффективного способа лазерной и светодиодной терапии возможна только в эксперименте. Это наиболее объективный способ для выбора адекватной методики воздействия на репаративные процессы кожи. Он позволяет не только проведение разнообразных морфологических методов изучения репаративных процессов под влиянием фототерапии, но и даёт возможность регулярно проводить визуальную и планиметрическую оценку процесса заживления ран.

В Республиканском специализированном центре хирургии им. академика В. Вахидова проводятся сравнительные экспериментальные исследования влияния различных типов низкоинтенсивного лазерного излучения (НИЛИ) и LED воздействий на стандартные дерматомные раны с использованием не только комплекса морфологических методов, но и оценки микроциркуляции, как в экспериментальных исследованиях, так и клинических наблюдениях. Изучение влияния LED воздействий на микроциркуляции с помощью ЛДФ сочетается с исследованием формы эритроцитов с использованием разработанного экспресс метода толстой капли (ЭМТК). Данная методика запатентована в Патентном ведомстве Республики Узбекистан «Способ определения форм эритроцитов» № МКИ 6 А 61 В 10/00, а также запатентована программа «Экспресс-диагностика форм эритроцитов» № ED-5-05.

ЭМТК находит всё более широкое применение для оценки формы эритроцитов для оценки формы эритроцитов в торакальной хирургии при 
миастении и её лечении, кардиохирургии и анестезиологии, эстетической хирургии, стоматологии дерматологии [4, 33], а также плазмаферезе [2, 34] и других разделах медицины [4, 7, 22, 27, 33]. Экспериментальные исследования показали, что структурные различия облученных и необлучённых (контрольных) дерматомных ран как при использовании НИЛИ, так и LED проявляются на 3 сутки (4-х кратное облучение). Эти исследования позволили установить, что стимулирующее действие сочетанного излучения синего, зелёного, в купе с инфракрасным диапазонами на заживление ран практически не уступаете действию гелий-неонов ( $\mathrm{He}-\mathrm{Ne})$, магнитоинфракрасной лазерной терапии (МИКЛТ) и других видов лазерного излучения [5, 29].

Проведенные планиметрические, светооптические, стереоморфометрические и электронномикроскопические исследования показали, что структурные различия облученных и необлучённых дерматомных ран как при использовании НИЛИ, так и LED проявляются на 3 сутки (4-х кратное облучение). Фотовоздействия снижают проявления альтерации и отёка уже в первые сутки. С 3-х суток воздействия проявляются отчётливые различия в морфологии контрольных ран и ран, облученных, как НИЛИ (ГНЛ и МИКЛТ), так и Барва-Флекс ЗИК, так и, особенно, Барва-Флекс СИК. Сравнительная оценка заживления дерматомных ран под влиянием НИЛИ (ГНЛ и МИКЛТ) и LED показали, что их противовоспалительные и стимулирующие репаративные процессы эффекты вполне сопоставимы.

Начатые в Республиканском специализированном центре хирургии им В. Вахидова клинико-морфологические исследования влияния LED-воздействий на репаративные процессы грудины после стернотомии показывают, что этот вид фототерапии не только предотвращает осложнения стернотомии, но и, в значительной мере, ускоряет процесс заживления грудины [13].

Bсе виды LED воздействий приводят к существенному улучшению показателей микроциркуляции и соотношения нормальных форм эритроцитов, дискоцитов и их патологических форм, как в зоне репаративного процесса, так и в периферической крови $[5,29]$. Доказанное стимулирующее влияние LED воздействий на микроциркуляцию и разработанные приспособления в виде «одеял» с источниками LED различной длины волны, позволяет полагать о целесообразности их использования в комплексном лечении, так называемого, синдрома «полиорганной недостаточности». Этот синдром нередко развивается у пациентов после 
оперативного лечения и обусловлен нарушениями микроциркуляции одновременно во многих органах.

Одна из проблем эстетической хирургии профилактика и лечение келоидных рубцов. Различные виды лазерных воздействий, в комплексе с медикаментозной терапией успешно используются в лечении келоидов [32]. Проведенные экспериментальные исследования и клинические наблюдения показали, что использование LED в комплексном лечении угревой болезни - одной из основных причин формирования рубцов и келоидов, дают выраженный положительный эффект в их предупреждении и лечении [5].

Проведенные ранее исследования показали, что различные патологические процессы сопровождаются не только существенными структурными изменениями соответствующих клеток, тканей и органов, но и выраженными нарушения в соотношении дискоцитов - нормальных эритроцитов и их патологических форм. Эти нарушения отмечаются как в периферической крови, полученной из пальца, так и, особенно, в крови, полученной из зон патологически измененной. Сдвиги в соотношении дискоцитов и патологических форм эритроцитов, наряду с изменения стенок капилляров, обусловливают выраженные нарушения микроциркуляции. LED воздействия способствуют стимуляции репаративных процессов, нормализации соотношения дискоцитов и ПФЭ, существенному улучшению параметров микроциркуляции.

Таким образом, анализ имеющихся данных по использованию светодиодных излучателей в медицинской практике показывает, что в отношении противовоспалительного и стимулирующего воздействия на процессы репарации кожи и неоваскулогенеза они обладают сопоставимой эффективностью по сравнению с НИЛИ. В сочетании с простотой использования и более низкой стоимостью LED матриц по сравнению практически со всеми типами лазеров можно утверждать, что они являются вполне адекватной альтернативой НИЛИ. В силу указанных свойств и особенностей, по нашему мнению, они должны занять свою нишу в фотомедицине, в том числе и комплексном лечении хирургической патологии.

\section{Список литературы}

1. Антиоксиданты и лазерное излучение в терапии ран и трофических язв / Толстых П.И., Клебанов Г.И., Шехтер А.Б. и др. М.: Издательский дом «ЭКО», 2002. $240 \mathrm{c}$. 
2. Байбеков И.М., Бутаев А.Х., Байбеков А.И. Лазерная допплеровская флоуметрия и возможности её использования для диагностики в хирургии // Вестник экстренной медицины. 2013. №2. С. 56-59.

3. Байбеков И.М., Бутаев А.Х., Саидханов Б.А. Сканирующая электронная микроскопия элементов фильтра «Роса» аппарата HEMOFENIX и крови при мембранном плазмаферезе и лазерном облучении // Вестник трансплантологии и искусственных органов. 2013. Т. 15. №2. С. 76-81.

4. Байбеков И.М., Ибрагимов А.Ф., Байбеков А.И. Влияние лазерного облучения донорской крови на форму эритроцитов // Бюллетень экспериментальной биологии и медицины. 2012. Т. 152. № 12. С. 702-706.

5. Байбеков И.М., Ибрагимов А.Ф., Хашимов Ф.Ф. Применение светодиодного излучении в комплексном лечении дерматозов и угрей // Материалы XXXIX Международной научно-практической конференции «Применение лазеров в медицине и биологии. Харьков, 2013. С. 17.

6. Байбеков И.М., Каракозов П.Е., Мардонов Д. Лазерные и светодиодные воздействия на раны при использовании различных шовных материалов // Лазерная медицина. 2016. Т. 20. № 3. С. 22.

7. Байбеков И.М., Стрижков Н.А. Влияние лазерного облучения крови во время искусственного кровообращения на форму эритроцитов // Лазерная медицина. 2012. Т. 16. № 1. С. 17-21.

8. Буйлин В.А., Ларюшин А.И., Никитина М.В., Свето-лазерная терапия. Тверь: ООО «Издательство «Триада», 2004. 256 с.

9. Бутаев А.X. Изменение формы эритроцитов при миастении и возможности лазерного облучения крови в ее коррекции // Лазерная медицина. 2011. № 4. 22-25.

10. Воздействие светодиодного излучения аппарата «Барва-Флекс СИК» на заживление экспериментальных ран / Байбеков И.М., Бутаев А.Х., Хашимов Ф.Ф., Марданов Д.Н., Байбеков А.И. // Фотобиология и фотомедицина. 2013. №1.2. С. 119-122.

11. Гамалея Н.Ф. Механизмы биологического действия излучения лазеров // Лазеры в клинической медицине [Под ред. С.Д. Плетнёва]. М.: «Медицина», 1996. С. 51-98.

12. Гейниц А.В., Москвин С.В., Азизов Г.А. Внутривенное лазерное облучение крови. М.: «Триада», 2006. С. 144.

13. Использование лазерного и светодиодного воздействия для стимуляции репаративных процессов грудины при стернотомии / Бутаев А.X. Ахмедов У.Б., Сабиров С.К., Худжамбердыев А.У. // Лазерная медицина. 2014. T.18. №4. C. 15. 
14. Калиш Ю.И., Шарипов У.К. Эффективность применения полупроводниковых лазеров в лечении рецидивных келоидных рубцов // Материалы научно-практической конференции «Современные достижения лазерной медицины и их применение в практическом здравоохранении». Москва, 2006. С. 40-41.

15. Карандашов В.И., Петухов Е.Б., Зродников В.С. Фототерапия (светолечение): руководство для врачей / Под ред. Н.Р. Палеева. М.: Медицина, 2001. 392 c.

16. Карташев В.П. Морфо-функциональные перестройки эритроцитов в постнатальном онтогенезе крыс (влияние стрессом индуцированного изменения гормонального статуса материнского организма во время беременности, экзогенных гидрокортизона и тироксина): Автореф. дис. канд. биол. наук. Ташкент, 1994. 28 с.

17. Карташев В.П., Эрстекис Г.А., Байбеков И.М. Влияние двигательного режима беременных на морфофункциональное состояние эритроцитов в постнатальном онтогенезе потомства // Эритроциты в норме, патологии и при лазерных воздействиях. Тверь: ООО «Издательство «Триада», 2008. С. 80-94.

18. Козлов В.И. Лазерная стимуляция микроциркуляции крови // Материалы научно-практической конференции «Современные достижения лазерной медицины и их применение в практическом здравоохранении». Москва, 2006. С. 174-175.

19. Коробов А.М., Коробов В.А., Лесная Т.А. Фототерапевтические аппараты Коробова серии «Барва». Харьков, 2010. 176 с.

20. Крупаткин А.И. Сидоров В.В. Лазерная допплеровская флоуметрия микроциркуляции крови. М.: Изд-во «Медицина», 2005. 256 с.

21. Морфологические аспекты лазерных воздействий (на хронические язвы и печень) / Байбеков И.М., Назыров Ф.Г., Ильхамов Ф.А. и др. Ташкент: Изд-во Мед. лит. им. Абу Али ибн Сино, 1996. 208 с.

22. Морфологические изменения эритроцитов при аппаратной реинфузии крови в коронарной хирургии / Назырова Л.А., Хайдаров А.Х., Байбеков И.М., Суванов А.А. // Анестезиология и реаниматология. 2009. №5. С. 5-8.

23. Москвин С.В. Основы лазерной терапии. - М. - Тверь: ООО «Издательство «Триада», 2016. - 896 с.

24. Плетнев С.Д. Лазеры в клинической медицине. М.: Медицина, 1996. 432 с.

25. Применение лазеров в амбулаторной хирургии / Калиш Ю.И., Макаров К.И., Садыков Р.А., Мадартов К.М., Хамраев А.Ж. Ташкент: Изд.им. Абу Али ибн Сино, 1997. 96 с. 
26. Развитие экспресс-методов флуоресцентной спектрометрии в клинической практике (возможности и перспективы) / Александров М.Т., Бажанов Н.Н., Каплун А.П., Кузьмин Г.П., Москаленко И.В., Шафеев Г.А., Швец В.И. // Материалы научно-практической конференции «Современные достижения лазерной медицины и их применение в практическом здравоохранении». Москва, 2006. С. 186-187.

27. Ризаева С.М., Байбеков И.М. Изменения формы эритроцитов при пародонтите и возможности лазеротерапии в их коррекции // Лазерная медицина. 2010. Т.14. № 4. С. 45-48.

28. Скобелкин О.К. Лазеры в хирургии. М.: Медицина, 1989. 256 с.

29. Структурные аспекты эффективности сочетанного использования внутрисосудистой и локальной лазерной терапии / Байбеков И.М., Ибрагимов А.Ф., Ризаева С.М., Хашимов Ф.Ф. // Материалы XXXYI Международной научно-практической конференции «Применение лазеров в медицине и биологии». Судак. 2011. С. 12.

30. Структурные изменения эндотелия и эритроцитов при внутрисосудистом лазерном облучении крови / Касымов А.Х., Хорошаев В.А., Карташев В.П., Байбеков И.М. // Морфологические основы низкоинтенсивной лазеротерапии [Под ред. В.И. Козлова, И.М. Байбекова]. Ташкент: Изд-во Ибн Сины, 1991. С. 100-115.

31. Хаджибаев А.М., Пулатов Д.Т., Байбеков И.М. Лазерные технологии в комплексном лечении ургентных осложнений дуоденальных язв // Лазерная медицина. 2016. Т. 20. № 3. С. 37.

32. Хашимов Ф.Ф., Байбеков И.М., Использование лазерных технологий в диагностике и комплексном лечении постугревых келоидных рубцов // Материалы. XXXYIII Международной научно-практической конференции «Применение лазеров в медицине и биологии. Ялта, 2012. С. 129.

33. Эритроциты в норме, патологии и при лазерных воздействиях / Байбеков И.М., Мавлян-Ходжаев Р.Ш., Эрстекис А.Г., Москвин С.В. Тверь: Изд-во «Триада», 2008. $256 \mathrm{c}$.

34. Al-Watban F. A.N., Zhang X.Y. Stimulative and inhibitory effects of low incident levels of argon laser energy on wound healing // Laser Therapy. 1995. Vol. 7, №1, pp. 11-18.

35. Hoffmann U. Evaluation of flux motion, Laser Doppler. London - Los Angeles - Nicosia: Med-Orion Publishing Company, 1994, pp. 55-61.

36. Li W.T., Chen H.L., Wang C.T. Effect of light emitting diode irradiation on proliferation of human bone marrow mesenchymal stem cells // Journal of Medical and Biological Engineering. 2006. Vol. 26. № 1, pp. 35-42. 
37. Li W.T., Leu Y.C., Wu J.L. Red-light emitting diode irradiationincreases the proliferation and osteogenic differentiation of rat bone marrow mesenchymal stem cells // Photomed. Laser Surg. 2010. Supp 1.1, pp. 157-165. DOI: 10.1089/pho.2009.2540.

38. NASA light emitting diode medical applications from deep space to deep sea / Whelan H.T., Buchmann E.V., Whelan N.T. et al. // Space Tech. \& App. Intern. Forum. 2001, pp. 35-45.

39. NASA light-emitting diode medical program - progress in space flight and terrestrial applications / Whelan H.T., Houle J.M., Whelan N.T. et al. // Space Tech. \& App. Internl. Forum. 2000, pp. 37-43.

40. Regulation of human cutaneous circulation evaluated by laser Doppler flowmetry, iontophoresis and spectral analysis: importance of nitric oxide and prostaglandins / Kvandal P., Stevanovska A., Veber M. et al. // Microvascular Research. 2003. Vol. 65, pp. 160-171.

41. Simunovic Z. (Ed-r) Lasers in medicine science and praxis in medicine, surgery dentistry and veterinary Trilogy updates with emphasis on LILT-photobiostimulation-photodynamic therapy and laser acupuncture. Locarno, 2009. P. 772.

42. Tuner J., Hode L. The New Laser Therapy Hand boor Prima book. Stockholm, 2010. P. 847.

\section{References}

1. Tolstykh P.I., Klebanov G.I., Shekhter A.B. et al. Antioksidanty i lazernoe izluchenie $v$ terapii ran $i$ troficheskikh yazv [Antioxidants and laser radiation in the therapy of wounds and trophic ulcers]. Moscow: Izdatelskiy dom «EKO», 2002. $240 \mathrm{p}$.

2. Baybekov I.M., Butaev A.Kh., Baybekov A.I. Lazernaya dopplerovskaya floumetriya i vozmozhnosti ee ispol'zovaniya dlya diagnostiki v khirurgii [Laser Doppler flowmetry and the possibility of its use for diagnosis in surgery]. Vestnik ekstrennoy meditsiny [Journal of emergency medicine], 2013, no. 2, pp. 56-59.

3. Baybekov I.M., Butaev A.Kh., Saidkhanov B.A. Skaniruyushchaya elektronnaya mikroskopiya elementov fil'tra «Rosa» apparata HEMOFENIX i krovi pri membrannom plazmafereze i lazernom obluchenii [Scanning electron microscopy of filter elements "Dew" of the device HEMOFENIX and blood in membrane plasmapheresis and laser irradiation]. Vestnik transplantologii $i$ iskusstvennykh organov [Vestnik of Transplantology and artificial organs]. 2013, Vol. 15, issue 2, pp. 76-81. 
4. Baybekov I.M., Ibragimov A.F., Baybekov A.I. Vliyanie lazernogo oblucheniya donorskoy krovi na formu eritrotsitov [The Influence of laser irradiation of blood in the shape of red blood cells]. Byulleten eksperimental'noy biologii $i$ meditsiny [Bulletin of experimental biology and medicine]. 2012, Vol. 152, issue 12 , pp. 702-706.

5. Baybekov I.M., Ibragimov A.F., Khashimov F.F. Primenenie svetodiodnogo izluchenii $\mathrm{v}$ kompleksnom lechenii dermatozov i ugrey [Application of led radiation in complex treatment of dermatoses and acne]. Materialy XXXIX Mezhdunarodnoy nauchno-prakticheskoy konferentsii «Primenenie lazerov $v$ meditsine $i$ biologii [Proc. XXXIXth International scientific-practical conference "Application of lasers in medicine and biology]. Kharkiv, 2013. P. 17.

6. Baybekov I.M., Karakozov P.E., Mardonov D. Lazernye i svetodiodnye vozdeystviya na rany pri ispol"zovanii razlichnykh shovnykh materialov [LED and laser effects on wound when using different suture materials]. Lazernaya meditsina [Laser medicine]. 2016, Vol. 20, issue 3. P. 22.

7. Baybekov I.M., Strizhkov N.A. Vliyanie lazernogo oblucheniya krovi vo vremya iskusstvennogo krovoobrashcheniya na formu eritrotsitov [The influence of laser irradiation of blood during artificial blood circulation on the shape of erythrocytes]. Lazernaya meditsina [Laser medicine]. 2012, Vol. 16, issue 1, pp. 17-21.

8. Buylin V.A., Laryushin A.I., Nikitina M.V., Sveto-lazernaya terapiya [Light-laser therapy]. Tver: OOO «Izdatelstvo «Triada», 2004. 256 p.

9. Butaev A.Kh. Izmenenie formy eritrotsitov pri miastenii i vozmozhnosti lazernogo oblucheniya krovi $\mathrm{v}$ ee korrektsii [The changing shape of the red blood cells in infants and the possibility of laser irradiation of the blood in its correction]. Lazernaya meditsina [Laser medicine]. 2011, no. 4, pp. 22-25.

10. Baybekov I.M., Butaev A.Kh., Khashimov F.F., Mardanov D.N., Baybekov A.I. Vozdeystvie svetodiodnogo izlucheniya apparata «Barva-Fleks SIK» na zazhivlenie eksperimental'nykh ran [The influence of led radiation apparatus "Barva-Fleks SIK" on healing of experimental wounds]. Fotobiologiya i fotomeditsina [Photobiology and photomedicine]. 2013, no. 1.2, pp. 119-122.

11. Gamaleya N.F. Mekhanizmy biologicheskogo deystviya izlucheniya lazerov [The mechanisms of biological action of laser radiation]. Lazery $v$ klinicheskoy meditsine [Laser in clinical medicine]. Ed. by P.D. Pletneva. Moscow: «Meditsina», 1996, pp. 51-98.

12. Geynits A.V., Moskvin S.V., Azizov G.A. Vnutrivennoe lazernoe obluchenie krovi [Intravenous laser irradiation of blood]. Moscow: «Triada», 2006. 144 p.

13. Butaev A.Kh. Akhmedov U.B., Sabirov S.K., Khudzhamberdyev A.U. Ispolzovanie lazernogo i svetodiodnogo vozdeystviya dlya stimulyatsii reparativnykh 
protsessov grudiny pri sternotomii [The use of laser and led effects for the stimulation of reparative processes of the sternum during sternotomy]. Lazernaya meditsina [Laser medicine]. 2014, Vol. 18, issue 4. P. 15.

14. Kalish Yu.I., Sharipov U.K. Effektivnost primeneniya poluprovodnikovykh lazerov v lechenii retsidivnykh keloidnykh rubtsov [The efficiency of the use of semiconductor lasers in the treatment of recurrent keloid scars]. Materialy nauchno-prakticheskoy konferentsii «Sovremennye dostizheniya lazernoy meditsiny $i$ ikh primenenie v prakticheskom zdravookhranenii» [Proc. scientific-practical conference "Modern achievements of laser medicine and their application in practical health care"']. Moscow, 2006, pp. 40-41.

15. Karandashov V.I., Petukhov E.B., Zrodnikov V.S. Fototerapiya (svetolechenie): rukovodstvo dlya vrachey [Phototherapy (light therapy): a guide for physicians]. Ed. N.R. Paleeva. Moscow: Meditsina, 2001. 392 p.

16. Kartashev V.P. Avtoref. dis. kand. biol. nauk. "Morfo-funktsional'nye perestroyki eritrotsitov $v$ postnatal'nom ontogeneze krys (vliyanie stressom indutsirovannogo izmeneniya gormonal'nogo statusa materinskogo organizma vo vremya beremennosti, ekzogennykh gidrokortizona i tiroksina)» [Morpho-functional reconstructions of red blood cells in postnatal ontogenesis of rats (influence of stress induced changes in hormonal status of the maternal organism during pregnancy, exogenous hydrocortisone and thyroxine)]. Tashkent, 1994. 28 p.

17. Kartashev V.P., Erstekis G.A., Baybekov I.M. Vliyanie dvigatel'nogo rezhima beremennykh na morfofunktsional'noe sostoyanie eritrotsitov v postnatal'nom ontogeneze potomstva [The Impact of motoring pregnant on the morphofunctional state of erythrocytes in the postnatal ontogenesis of the progeny]. Eritrotsity $v$ norme, patologii i pri lazernykh vozdeystviyakh [The erythrocytes in norm, pathology and laser effects]. Tver: OOO "Izdatelstvo "Triada", 2008, pp. 80-94.

18. Kozlov V.I. Lazernaya stimulyatsiya mikrotsirkulyatsii krovi [Laser stimulation of blood microcirculation]. Materialy nauchno-prakticheskoy konferentsii «Sovremennye dostizheniya lazernoy meditsiny $i$ ikh primenenie $v$ prakticheskom zdravookhranenii» [Proc. scientific-practical conference "Modern achievements of laser medicine and their application in practical health care"]. Moscow, 2006, pp. 174-175.

19. Korobov A.M., Korobov V.A., Lesnaya T.A. Fototerapevticheskie apparaty Korobova serii «Barva» [Phototherapeutic apparatus series Korobov "Barva”]. Kharkiv, 2010. 176 p.

20. Krupatkin A.I. Sidorov V.V. Lazernaya dopplerovskaya floumetriya mikrotsirkulyatsii krovi [Laser Doppler flowmetry of blood microcirculation]. Moscow: Izd-vo «Meditsina», 2005. 256 p. 
21. Baybekov I.M., Nazyrov F.G., Il'khamov F.A. et al. Morfologicheskie aspekty lazernykh vozdeystviy (na khronicheskie yazvy i pechen) [Morphological aspects of the laser impacts (chronic ulcers, and liver)]. Tashkent: Izd-vo Med. lit. im. Abu Ali ibn Sino, 1996. 208 p.

22. Nazyrova L.A., Khaydarov A.Kh., Baybekov I.M., Suvanov A.A. Morfologicheskie izmeneniya eritrotsitov pri apparatnoy reinfuzii krovi v koronarnoy khirurgii [Morphological changes of erythrocytes in hardware reinfusion of blood in coronary surgery]. Anesteziologiya i reanimatologiya [Anesthesiology and reanimatology]. 2009, no. 5, pp. 5-8.

23. Moskvin S.V. Osnovy lazernoy terapiya [Fundamentals of laser therapy]. Moscow. Tver: Izd. Triada, 2016. 896 p.

24. Pletnev C.D. Lazery v klinicheskoy meditsine [Lasers in clinical medicine]. Moscow: Meditsina, 1996. 432 p.

25. Kalish Yu.I., Makarov K.I., Sadykov R.A., Madartov K.M., Khamraev A.Zh. Primenenie lazerov $v$ ambulatornoy khirurgii [The use of lasers in ambulatory surgery]. Tashkent: Izd.im. Abu Ali ibn Sino, 1997. 96 p.

26. Aleksandrov M.T., Bazhanov N.N., Kaplun A.P., Kuz'min G.P., Moskalenko I.V., Shafeev G.A., Shvets V.I. Razvitie ekspress-metodov fluorestsentnoy spektrometrii v klinicheskoy praktike (vozmozhnosti i perspektivy) [The development of rapid methods for fluorescent spectrometry in clinical practice (possibilities and prospects)]. Materialy nauchno-prakticheskoy konferentsii «Sovremennye dostizheniya lazernoy meditsiny $i$ ikh primenenie v prakticheskom zdravookhranenii» [Proc. scientific-practical conference "Modern achievements of laser medicine and their application in practical health care"]. Moscow, 2006, pp. 186-187.

27. Rizaeva S.M., Baybekov I.M. Izmeneniya formy eritrotsitov pri parodontite i vozmozhnosti lazeroterapii $\mathrm{v}$ ikh korrektsii [Shape changes of erythrocytes of periodontitis and the possibility of laser therapy in their correction]. Lazernaya meditsina [Laser medicine]. 2010. Vol.14, issue 4, pp. 45-48.

28. Skobelkin O.K. Lazery v khirurgii [Lasers in surgery]. Moscow: Meditsina, 1989. $256 \mathrm{p}$.

29. Baybekov I.M., Ibragimov A.F., Rizaeva S.M., Khashimov F.F. Strukturnye aspekty effektivnosti sochetannogo ispol'zovaniya vnutrisosudistoy i lokal'noy lazernoy terapii [Structural aspects of efficiency of combined use of intravascular and local laser therapy]. Materialy XXXYI Mezhdunarodnoy nauchno-prakticheskoy konferentsii "Primenenie lazerov $v$ meditsine $i$ biologii» [Proc. XXXYIth International scientific-practical conference "Application of lasers in medicine and biology"]. Sudak. 2011. P. 12. 
30. Kasymov A.Kh., Khoroshaev V.A., Kartashev V.P., Baybekov I.M. Strukturnye izmeneniya endoteliya i eritrotsitov pri vnutrisosudistom lazernom obluchenii krovi [Structural changes of endothelium and of erythrocytes with intravascular laser irradiation of blood]. Morfologicheskie osnovy nizkointensivnoy lazeroterapii [Morphological basis of the low-intensity laser therapy]. Ed. by V.I. Kozlova, I.M. Baybekova. Tashkent: Izd-vo Ibn Siny, 1991, pp. 100-115.

31. Khadzhibaev A.M., Pulatov D.T., Baybekov I.M. Lazernye tekhnologii v kompleksnom lechenii urgentnykh oslozhneniy duodenalnykh yazv [Laser technologies in treatment of urgent complications of duodenal ulcers]. Lazernaya meditsina [Laser medicine]. 2016, Vol. 20, issue 3. P. 37.

32. Khashimov F.F., Baybekov I.M. Ispolzovanie lazernykh tekhnologiy v diagnostike i kompleksnom lechenii postugrevykh keloidnykh rubtsov [The application of laser technologies in diagnostics and complex treatment of keloid scars post-acne]. Materialy. XXXYIII Mezhdunarodnoy nauchno-prakticheskoy konferentsii «Primenenie lazerov v meditsine i biologii» [Proc. XXXYIIIth International scientific-practical conference "Application of lasers in medicine and biology»]. Yalta, 2012. 129 p.

33. Baybekov I.M., Mavlyan-Khodzhaev R.Sh., Erstekis A.G., Moskvin S.V. Eritrotsity v norme, patologii i pri lazernykh vozdeystviyakh [Erythrocytes in norm, pathology and under laser exposure]. Tver: Izd-vo «Triada», 2008. 256 p.

34. Al-Watban F. A.N., Zhang X.Y. Stimulative and inhibitory effects of low incident levels of argon laser energy on wound healing. Laser Therapy. 1995. Vol. 7, №1, pp. 11-18.

35. Hoffmann U. Evaluation of flux motion, Laser Doppler. London - Los Angeles - Nicosia: Med-Orion Publishing Company, 1994, pp. 55-61.

36. Li W.T., Chen H.L., Wang C.T. Effect of light emitting diode irradiation on proliferation of human bone marrow mesenchymal stem cells. Journal of Medical and Biological Engineering. 2006. Vol. 26. № 1, pp. 35-42.

37. Li W.T., Leu Y.C., Wu J.L. Red-light emitting diode irradiationincreases the proliferation and osteogenic differentiation of rat bone marrow mesenchymal stem cells. Photomed. Laser Surg. 2010. Supp 1.1, pp. 157-165. DOI: 10.1089/ pho.2009.2540.

38. Whelan H.T., Buchmann E.V., Whelan N.T. et al. NASA light emitting diode medical applications from deep space to deep sea. Space Tech. \& App. Intern. Forum. 2001, pp. 35-45.

39. Whelan H.T., Houle J.M., Whelan N.T. et al. NASA light-emitting diode medical program - progress in space flight and terrestrial applications. Space Tech. \& App. Internl. Forum. 2000, pp. 37-43. 
40. Kvandal P., Stevanovska A., Veber M. et al. Regulation of human cutaneous circulation evaluated by laser Doppler flowmetry, iontophoresis and spectral analysis: importance of nitric oxide and prostaglandins. Microvascular Research. 2003. Vol. 65, pp. 160-171.

41. Simunovic Z. (Ed-r) Lasers in medicine science and praxis in medicine, surgery dentistry and veterinary Trilogy updates with emphasis on LILT-photobiostimulation-photodynamic therapy and laser acupuncture. Locarno, 2009. P. 772.

42. Tuner J., Hode L. The New Laser Therapy Hand boor Prima book. Stockholm, 2010. P. 847.

\section{ДАННЫЕ ОБ АВТОРАХ}

Байбеков Искандер Мухамедович, доктор медицинских наук, профессор, руководитель лаборатории патологической анатомии Республиканский спещичализированньій иентр хирургии имени академика В. Вахидова

ул. Фархадская, 10, г. Ташкент, 700115, Республика Узбекистан surgery@minzdrav.uz

Карташев Валерий Пантелеевич, доцент кафедры адаптивной физической культуры и рекреации, кандидат биологических наук, профессор Российский государственный социальный университет ул. Лосиноостровская, 24, г. Москва, 107150, Российская Федерация kvpmos@mail.ru

Пулатов Дильмурод Тухтабоевич, стажер исследователь Республиканский научный центр экстренной медицинской помощи ул. Фархадская, 2, г. Ташкент, 700115, Республика Узбекистан surgery@minzdrav.uz

Бутаев Азамат Хасанджанович, младший научный сотрудник лаборатории патологической анатомии

Республиканский специализированный центр хирургии имени академика В. Вахидова ул. Фархадская, 10, г. Ташкент, 700115, Республика Узбекистан surgery@minzdrav.uz

\section{DATA ABOUT THE AUTHORS}

Baybekov Iskander Mukhamedovich, Doctor of Medicine, Professor, Head of the Laboratory of Pathological Anatomy 
Republican Specialized Surgery Center named after academician V. Vakhidov

10, Farkhadskaya Str., Tashkent, 700115, Uzbekistan Republic

Scopus Author ID: 36835303400

Kartashev Valery Panteleevich, Docent of the Department of Adaptive Physical Education and Recreation, $\mathrm{PhD}$ in Biology, Professor

Russian State Social University,

24, Losinoostrovskaya Str., Moscow, 107150, Russian Federation

kvpmos@mail.ru

SPIN-code: 6284-4890

ORCID: 0000-0001-8539-5264

Scopus Author ID: 57073261500

Butaev Azamat Khasanjani, Junior Researcher of Laboratory of Pathological Anatomy

Republican Specialized Surgery Center named after academician $V$. Vakhidov

10, Farkhadskaya Str., Tashkent, 700115, Uzbekistan Republic

Scopus Author ID: 39760969500 